\title{
IL-1 $\alpha$ Causes Lung Inflammation and Maturation by Direct Effects on Preterm Fetal Lamb Lungs
}

\author{
ILENE R.S. SOSENKO, SUHAS G. KALLAPUR, ILIAS NITSOS, TIMOTHY J.M. MOSS, JOHN P. NEWNHAM, \\ MACHIKO IKEGAMI, AND ALAN H. JOBE
}

\begin{abstract}
Department of Pediatrics [I.R.S.S.], University of Miami School of Medicine, Miami, FL 33106; Division of Pulmonary Biology [S.G.K., MI, A.H.J.], Cincinnati Children's Hospital Medical Center, University of Cincinnati, Cincinnati, OH 45229; School of Women's and Infants' Health [I.N., T.J.M.M., J.P.N.], The University of Western Australia, Crawley 6009, Western Australia, Australia
\end{abstract}

\begin{abstract}
Intra-amniotic endotoxin induces IL-1, causes chorioamnionitis, lung inflammation, lung injury and lung maturation in preterm lambs. Intra-amniotic IL- $1 \alpha$ also causes chorioamnionitis, lung inflammation and lung maturation. We asked if IL-1 $\alpha$ effects on the preterm lung are mediated by direct signaling to the lung rather than by indirect effects from the chorioamnionitis. To study IL-1 effects independently of chorioamnionitis, the lungs and the amniotic fluid were surgically separated in fetal sheep by diverting fetal lung fluid via a tracheostomy tube to a sialastic bag. A mini-osmotic pump delivered an intratracheal infusion of recombinant sheep IL-1 $\alpha$ (10 $\mu \mathrm{g}$ ) or saline (control) over $24 \mathrm{~h}$. Preterm lambs were delivered $1 \mathrm{~d}$ or $7 \mathrm{~d}$ after the start of the infusion at $124 \mathrm{~d}$ gestational age $($ Term $=$ $150 \mathrm{~d})$. IL-1 $\alpha$ recruited inflammatory cells and increased proinflammatory cytokine mRNA expression in the fetal lungs. Compared with controls, IL- $1 \alpha$ did not alter lung antioxidant enzyme activity or alveolar numbers. IL- $1 \alpha$ had minimal effects on the mRNA or protein expression of proteins essential for vascular development. IL- $1 \alpha$ induced large increases in alveolar surfactant saturated phosphatidylcholine and increased lung gas volumes. Lung inflammation and maturation result from direct exposure of the fetal lung to a single cytokine - IL- $1 \alpha$. (Pediatr Res 60: 294-298, 2006)
\end{abstract}

$\mathrm{L}^{2}$ ate gestational maturation prepares the fetal lung for postnatal survival with the development of saccules/ alveoli and a lung microvasculature, increases in surfactant and increases in lung antioxidant enzymes (AOE) $(1,2)$. A reduction in respiratory distress syndrome in preterm infants, reflecting early lung maturation, has been associated with antenatal treatment with corticosteroids and with intrauterine infection and/or inflammation $(3,4)$. This inflammationinduced fetal lung maturation has been explored in fetal sheep using intra-amniotic injections of the pro-inflammatory agents E.coli endotoxin and IL-1 $(5,6)$.

We previously showed that intra-amniotic endotoxin caused chorioamnionitis and induced expression of IL-1 in the chorioamnion and fetal lung $(7,8)$. Using surgical procedures to separate the fetal lung from the amniotic fluid, we further

Received March 6, 2006; accepted April 30, 2006.

Correspondence: Alan H. Jobe, M.D., Ph.D., Cincinnati Children's Hospital, Division of Pulmonary Biology, 3333 Burnet Avenue, Cincinnati, OH 45229-3039; e-mail: alan.jobe@cchmc.org

Supported by grant HL-65397, K08 grant HL-70711 to S.K. HL-70711 from the National Institutes of Health and by the Women's and Infants' Health Research Foundation of Western Australia.

DOI: $10.1203 / 01 . p d r .0000233115 .51309 . d 3$ demonstrated that direct lung exposure to endotoxin could induce both inflammation and lung maturation without chorioamnionitis (9). However, endotoxin-induced production of IL-1 or other mediators by the chorioamnion or fetal lung may be important for initiating or amplifying the inflammation and maturation signals. Intra-amniotic IL-1 also causes chorioamnionitis and induces lung maturation (6). We hypothesized that IL-1 effects on the fetal lung are mediated by direct signaling without the requirement of chorioamnionitis.

Although the endotoxin TLR-4 receptor and the IL-1 receptor are similar and share components (10), the agonists for these receptors do not induce equivalent responses in the fetal lung. For example, endotoxin induces inflammatory cell recruitment to the fetal lung by a CD-18 dependent mechanism while inflammatory cell recruitment by IL- 1 is CD-18 independent (11). Endotoxin effects on the fetal lung include potentially adverse responses such as inflammation, decreased alveolar septation and microvascular injury and potentially beneficial effects such as induction of AOEs, modulation of innate immunity, and induced lung maturation (7,12-14). The pattern of responses of the fetal lung to the direct administration of IL-1 has not been evaluated. The objectives of this study were to evaluate inflammatory, morphologic, vascular, AOE and surfactant changes to direct IL-1 infusion in the fetal lung.

\section{METHODS}

Animals, surgery, and delivery. The Animal Experimentation Ethics Committees at the Cincinnati Children's Hospital Medical Center and the Western Australia Department of Agriculture approved these studies with fetal sheep. Date-bred singleton Merino ewes in Western Australia were pre-anesthetized with ketamine $(20 \mathrm{mg} / \mathrm{kg}, \mathrm{im})$ and xylazine $(0.2 \mathrm{mg} / \mathrm{kg}, \mathrm{im})$ and anesthesia was maintained with $1.5-2 \%$ halothane in $\mathrm{O}_{2}$. Aseptic surgery was performed to isolate the fetal respiratory system from the amniotic sac, silicone tubing was secured in the fetal trachea to allow collection of the fetal lung fluid into a 2-L sialastic bag (9). In the intratracheal IL-1 (IT IL-1) group, an osmotic infusion pump (Alzet 2001D, Alza Corp, Palo Alto, CA) was used to infuse $10 \mu \mathrm{g}$ of recombinant ovine IL- $1 \alpha$ (6) or saline over $24 \mathrm{~h}$ via a short

Abbreviations: AOE, antioxidant enzymes; BALF, bronchoalveolar lavage fluid; CAT, catalase; GP, glutathione peroxidase; RUL, right upper lobe; Sat PC, Saturated phosphatidylcholine; SOD, Superoxide dismutase 
length of vinyl tubing in the distal trachea as described previously (9). In a second experiment that was previously reported, $1 \mathrm{mg}$ E. coli endotoxin (IT endo) or saline over $24 \mathrm{~h}$ was infused into the trachea (9). We report here previously unpublished measurements of AOE activity for this second group of animals. The ewes were sedated at gestational d $124 \pm 1$ for delivery $1 \mathrm{~d}$ or $7 \mathrm{~d}$ after the surgery with ketamine (1g IM) and xylazine (25 mg IM) followed by spinal anesthesia ( $2 \%$ lidocaine, $3 \mathrm{~mL}$ ). Each fetus was delivered by cesarean section, given a lethal dose of pentobarbital and exsanguinated. Deflation pressure-volume curves then were performed after inflating the lungs with air to $40 \mathrm{~cm} \mathrm{H}_{2} 0$ pressure (5).

Processing of lungs. The lungs were removed from the chest and weighed. The left lung was lavaged three times with a volume of saline at $4^{\circ} \mathrm{C}$ that fully distended the lungs (5). Total cell counts in bronchoalveolar lavage fluid (BALF) were performed using Trypan blue exclusion to identify dead cells, followed by differential counts on cytospin preparations stained with DiffQuick (Dade Behring, Dudington, Switzerland) (15). BALF was used for surfactant lipid analysis. Tissue from the right lower lobe was frozen in liquid nitrogen for later protein and mRNA analysis. The right upper lobe was inflation fixed by bronchial instillation with $10 \%$ formalin at $30 \mathrm{~cm} \mathrm{H}_{2} \mathrm{O}$ pressure for morphometric analysis.

Surfactant lipid measurements. The lavage fluid was pooled, lipids extracted with chloroform:methanol, and saturated phosphatidylcholine (Sat PC) isolated using osmium tetroxide (16) and quantified by phosphorus assay (17).

Antioxidant enzyme measurements. Minimal residual blood remained in the lung tissue because the lambs had been exsanguinated (14). Thawed lung tissue was weighed, homogenized in cold PBS (1:10-1:20 wt/vol; Brinkmann Polytron, Westbury, NY), and centrifuged at $15,000 \mathrm{rpm}$ for $45 \mathrm{~min}$. The supernatants were assayed for AOEs by standard spectrophotometric techniques. Total superoxide dismutase (SOD) was measured using the xanthine/ xanthine oxidase method, whereby SOD activity is assayed by inhibition of the reduction of cytochrome $c$ in the xanthine oxidase reaction (18). Catalase (CAT) was measured as the rate of reduction of hydrogen peroxide at $240 \mathrm{~nm}$ (19). Glutathione peroxidase (GP) was quantified as the rate of oxidation of $\mathrm{NADPH}$ at $340 \mu \mathrm{m}$ using cumene hydroperoxide as substrate (20). Lung homogenates were also assayed for total DNA content (21), and AOE activities were expressed as units/mg lung tissue DNA. Assays were performed in parallel for tissue collected from the lambs exposed to intratracheal endotoxin (9).

mRNA analyses. Total RNA isolated from lung tissue was used for multiprobe RNAse protection analysis (7). Sheep specific riboprobes for IL-1 $\beta$, Il-6, IL-8 (7), VEGF, PECAM-1, Tie-1 (12) Tie-2 and VEGFR2 were described (15). For all the RNAse protection assays, ovine ribosomal protein L32 was used as an internal standard. Aliquots of $10 \mu \mathrm{g}$ of total RNA were hybridized with excess $\left.{ }^{32} \mathrm{P}\right]$ UTP (Life Sciences Products, Boston, MA) radiolabeled probes at $55^{\circ} \mathrm{C}$ for $18 \mathrm{~h}$. Single-stranded RNA was digested with RNAse A/RNAse T1 (Pharmingen, San Diego CA). RNAse was then inactivated and protected RNA was precipitated using RPA III ${ }^{\mathrm{TM}}$ inactivation/ precipitation buffer (Ambion, Austin TX). The protected fragments were electrophoresed on a $6 \%$ polyacrylamide-urea sequencing gel and visualized by autoradiography. The protected bands were quantified on a PhosphorImager using ImageQuant software (Molecular Dynamics, Sunnyvale, CA).

Evaluations of vascular proteins. Frozen lung samples were homogenized in ice-cold buffer containing protease inhibitors (12). Briefly, the samples were sonicated, centrifuged and the protein content in the supernatant was determined by the BCA method. Fifty $\mu \mathrm{g}$ of protein sample per lane was resolved by 3\% to $8 \%$ Tris-Acetate gel electrophoresis (Novex precast gels, Invitrogen, Carlsbad CA) and proteins from the gels were transferred to PVDF membrane by electroblotting (Invitrogen, Carlsbad CA). The blots were incubated with the primary antibody overnight at $4^{\circ} \mathrm{C}$ using one of the following antibodies diluted in blocking buffer: mouse monoclonal anti-eNOS antibody (Transduction Labs, Lexington KY), goat polyclonal anti-PECAM-1 antibody (sc-1505), rabbit polyclonal anti-Tie-2 antibody (sc-324) or rabbit polyclonal anti-VEGFR2 antibody (sc-504) (all antibodies from Santa Cruz Biotechnology, CA). Blots were incubated for $1 \mathrm{~h}$ at room temperature with the appropriate conjugated secondary antibody. After washing, bands were visualized by chemiluminescence (ECL kit; Amersham Pharmacia Biotech, Buckinghamshire, UK) and radiographed. The autoradiographs were scanned at high resolution and images acquired using Adobe Photoshop software. Densitometric quantitation was performed using ImageQuant v1.2 software (Molecular Dynamics, Sunnyvale, CA).

Lung morphometry. As lung maturation is known to vary between regions of the lung all morphometric analysis was performed on the right upper lobe (RUL). Morphometric analysis was performed on lungs receiving either intratracheal IL-1 or saline. Fixed lobe volume (FLV) was measured by the volume displacement method of Scherle (22). Each RUL was cut into 5-mm serial transverse sections and 3 randomly selected and uniformly spaced sections were then paraffin-embedded. The paraffin-embedded sections were then cut (5- $\mu \mathrm{m}$ thickness) and stained with hematoxylin and eosin (H\&E) for morphometric measurements.

Stained sections of lung were enlarged and printed onto photographic paper. A cycloid point counting grid (72 lines/144 points) was superimposed onto each photographic image to calculate the volume fraction of lung parenchyma (alveoli and alveolar ducts), non-parenchyma (blood vessels and conducting airways), interlobular septa (interstitial tissue forming distinct lobulation of the lung) and pleura. The volume fraction of these variables was calculated using the formula $\mathrm{Pi} / \mathrm{Pt}$ where $\mathrm{Pi}$ is the number of points hitting the structure of interest and $\mathrm{Pt}$ is equal to the total number of points that where superimposed over the entire lung. The parenchymal, non-parenchymal, interlobular septa and pleura volumes per lobe were calculated by multiplying the FLV by the appropriate volume fraction variable.

From each 5- $\mu \mathrm{m} \mathrm{H} \& \mathrm{E}$-stained section, 10 non-overlapping digital images were captured at a final magnification of $\times 850$ using a Spot RT digital camera interfaced with an Olympus BX51 microscope and computer. The number of points that fell on alveolar septal tissue and airspace, and the number of air-tissue intercepts where counted by superimposing a linear point counting grid (40 lines/80 points) using the method described by Willet et al. $(23,24)$. Surface fraction (Sv) which is the surface area of alveoli and alveolar ducts per unit volume of alveolar tissue, total alveolar surface area of the RUL, alveolar wall thickness, numerical density, total number of alveoli in the RUL and average alveolar volume were determined using the methods and equations described previously $(23,24)$.

Statistics. Values are expressed as means \pm SE. Normally distributed data were compared by ANOVA, using the Student-Newman-Keuls method for multiple comparisons. Data not normally distributed were compared using Kruskal-Wallis one-way ANOVA of ranks, with pair wise multiple comparisons using Dunn's procedure. A $p$-value $<0.05$ was considered statistically significant.

\section{RESULTS}

Physiologic variables at birth. The control lambs given saline and lambs exposed to IL- $1 \alpha$ had similar body weights, lung to body weight ratios and cord blood gases (Table 1). There were no fetal deaths.

Inflammation. Fetal lung inflammation was evaluated by assessing recruitment of leukocytes to the BALF and expression of pro-inflammatory cytokines in fetal lung tissue. Relative to controls, neutrophils and monocytes in BALF were increased on $1 \mathrm{~d}$ and $7 \mathrm{~d}$ after intratracheal IL- $1 \alpha$ (Fig. 1A). The mRNAs for pro-inflammatory cytokines IL- $1 \beta$, IL- 8 and IL-6 were induced 4-11 fold over control $1 \mathrm{~d}$ after intratracheal IL-1 $\alpha$ (Fig. 1B).

Expression of vascular proteins. Expression of proteins known to be essential for vascular development were evaluated both at the mRNA and protein level. VEGFR2, Tie-1, Tie-2, PECAM-1 and VEGF 165 isoform mRNA expression were not different between groups (Table 2). There was a $40 \%$

Table 1. Physiological variables of preterm lambs at birth

\begin{tabular}{llcccc}
\hline \multicolumn{1}{c}{ Group } & $\mathrm{N}$ & Body weight $(\mathrm{kg})$ & Lung/Body weight & Cord blood pH & Cord blood pCO2 (mmHg) \\
\hline Control (saline) (1d and 7d) & 9 & $2.53 \pm 0.10$ & $0.033 \pm 0.003$ & $7.28 \pm 0.01$ & $65 \pm 2.5$ \\
Intratracheal IL-1 (1d) & 4 & $2.55 \pm 0.2$ & $0.037 \pm 0.003$ & $7.28 \pm 0.03$ & $60 \pm 4.7$ \\
Intratracheal IL-1 (7d) & 7 & $2.61 \pm 0.17$ & $0.037 \pm 0.001$ & $7.28 \pm 0.02$ & $70 \pm 4.7$ \\
\hline
\end{tabular}

Lambs in all the groups were delivered at $124 \pm 1$ day gestational age. 

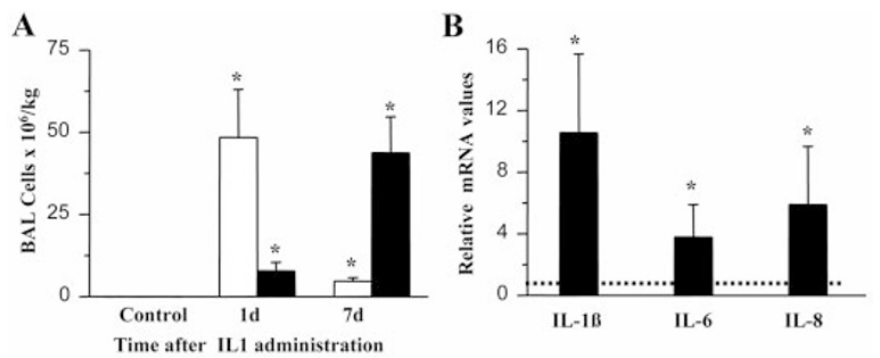

Figure 1. Intratracheal IL-1 induces lung inflammation. (A) Inflammatory cells in bronchoalveolar lavage (BAL) fluid of preterm lambs were counted 1d and $7 \mathrm{~d}$ after exposure to intratracheal IL-1. Cell counts are expressed per kilogram body weight. Neutrophils $(\square)$ and monocytes ( $\square$ ) were $<10^{4} / \mathrm{kg}$ in control BAL fluid. (4-9 animals per group, ${ }^{*} p<0.05$ versus control). (B) IL-1 $\beta$, IL-6 and IL-8 mRNA in lung tissue from preterm lambs $1 \mathrm{~d}$ after intratracheal IL-1 exposure were quantified by RNAse protection assays. The mRNA values were normalized to L32 (ribosomal protein mRNA). The mean mRNA signal in control animals was given a value of 1 (shown as a dashed line) and levels for each mRNA were expressed as values relative to controls (4-6 animals per group, ${ }^{*} p<0.05$ versus control).

Table 2. Effect of IT IL-1 exposure on expression of vascular markers in fetal lung

\begin{tabular}{llcc}
\hline & Control & IT IL-1 (1d) & IT IL-1 (7d) \\
\hline mRNA Values & & & \\
PECAM-1 & $1.0 \pm 0.12$ & $1.12 \pm 0.07$ & $1.44 \pm 0.09$ \\
Tie-1 & $1.0 \pm 0.2$ & $1.4 \pm 0.08$ & $1.9 \pm 0.14$ \\
Tie-2 & $1.0 \pm 0.07$ & $0.9 \pm 0.15$ & $1.07 \pm 0.1$ \\
VEGFR2 & $1.0 \pm 0.1$ & $0.7 \pm 0.1$ & $1.02 \pm 0.06$ \\
VEGF-165 isoform & $1.0 \pm 0.1$ & $0.9 \pm 0.06$ & $1.33 \pm 0.07$ \\
VEGF-188 isoform & $1.0 \pm 0.08$ & $0.57 \pm 0.04^{*}$ & $0.97 \pm 0.04$ \\
Protein Values & & & \\
PECAM-1 & $1.0 \pm 0.08$ & $0.79 \pm 0.04$ & $0.8 \pm 0.05$ \\
Tie-2 & $1.0 \pm 0.3$ & $0.62 \pm 0.06^{*}$ & $0.7 \pm 0.03^{*}$ \\
VEGFR2 & $1.0 \pm 0.16$ & $1.04 \pm 0.2$ & $0.99 \pm 0.12$ \\
eNOS & $1.0 \pm 0.04$ & $0.7 \pm 0.1$ & $0.87 \pm 0.08$ \\
\hline
\end{tabular}

(Relative to saline group, value $=1$ ).

$* p<0.05$ versus saline.

decrease in VEGF 188 isoform mRNA expression at 1d but not at $7 \mathrm{~d}$ after IL- $1 \alpha$ exposure. Of the proteins evaluated, only Tie-2 decreased $30-40 \%$ at both $1 \mathrm{~d}$ and $7 \mathrm{~d}$ after IL- $1 \alpha$ exposure, but eNOS, VEGFR2 and PECAM-1 protein expression were unchanged. This pattern of responses suggests minimal and transient effects of the intratracheal IL- 1 on the developing lung vasculature.

AOE activity. AOE activity was measured for the intratracheal IL-1 exposed lambs and the previously reported parallel experiment using intratracheal endotoxin (9). We measured AOE enzyme activity at $7 \mathrm{~d}$ because AOE enzymes do not increase at $1 \mathrm{~d}$ after intra-amniotic endotoxin (14). Intratracheal IL-1 exposure did not increase SOD, CAT or GP activities $7 \mathrm{~d}$ after exposure (Fig. 2). In contrast, intratracheal exposure to endotoxin increased CAT and GP activities at $7 \mathrm{~d}$.

Lung morphometry. The right upper lobe volumes $(\mathrm{mL} / \mathrm{kg})$ were $4.0 \pm 0.6$ for the saline group versus $4.5 \pm 0.4$ for the IT IL- $1 \alpha$ exposed group ( $p=0.5 \mathrm{NS}$ ). Lung surface area, alveolar numbers, alveolar numeric density and alveolar wall thickness were not different between IL- $1 \alpha$ and control groups $7 \mathrm{~d}$ after the surgery and intratracheal exposures (Fig. 3).

Maturation. Compared with controls, the Sat PC pool size increased by 4 -fold at $1 \mathrm{~d}$ and by 19 -fold at $7 \mathrm{~d}$ after IL- $1 \alpha$

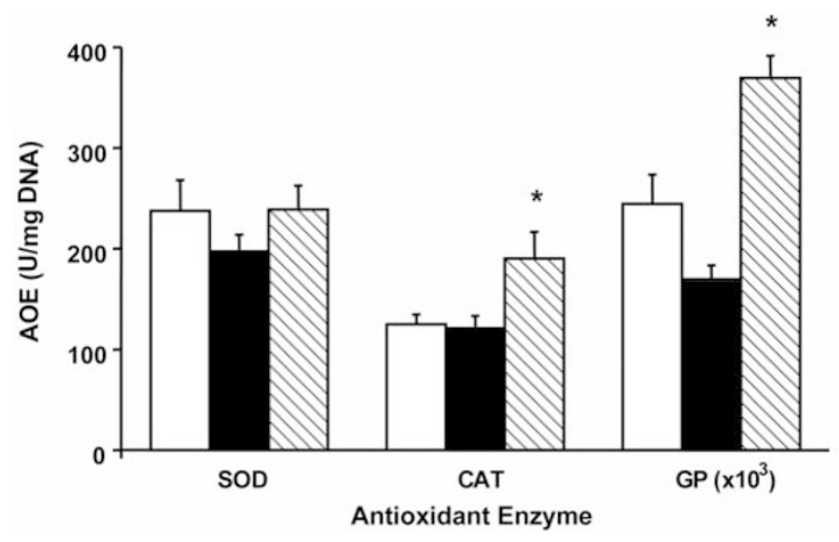

Figure 2. Intratracheal IL-1 did not increase AOE activity. Anti-oxidant enzyme activity in lung tissue from fetal sheep $7 \mathrm{~d}$ after intratracheal infusions of IL- $1 \alpha$ or endotoxin. The antioxidant enzyme activities of superoxide dismutase (SOD), catalase (CAT) and glutathione peroxidase (GP) were not increased by IL-1 $\alpha(\square)$ relative to controls $(\square)$. The endotoxin exposure ( $\mathbb{Q}$ ) increased CAT and GP relative to control and IL- $1 \alpha .{ }^{*} p<0.05$
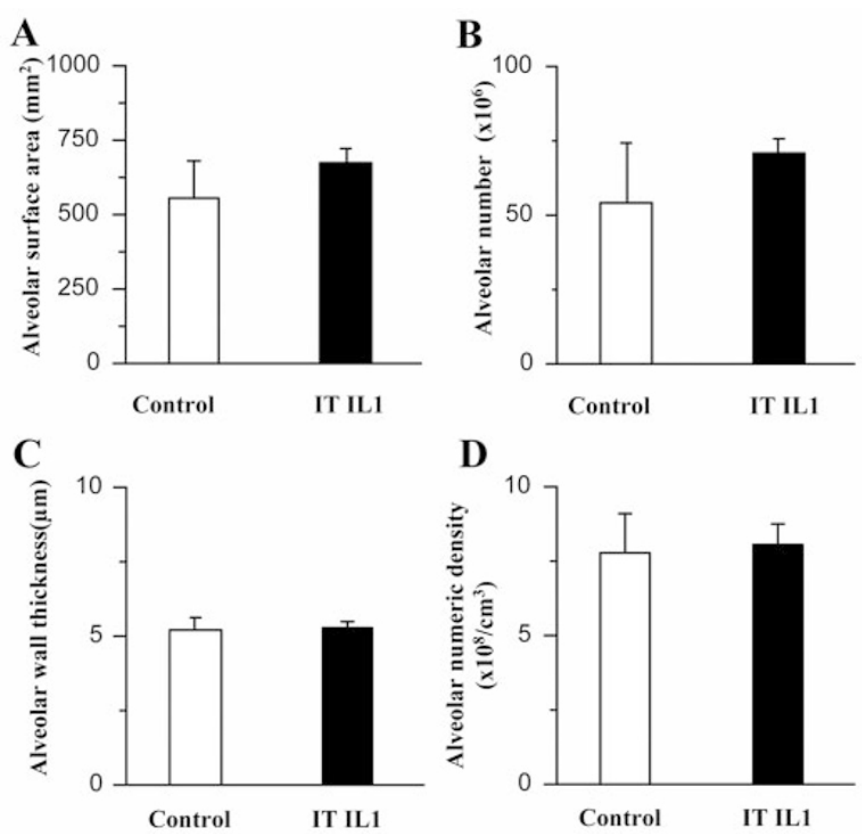

Figure 3. Intratracheal IL-1 did not cause morphometric changes in the fetal lung. Lung morphometry was performed for 5 controls $(\square)$ and for 5 lungs $7 \mathrm{~d}$ after exposure to intratracheal IL-1 (IT IL-1 - $\square$ ). There were no differences between the groups for alveolar surface area $(A)$, alveolar number $(B)$, alveolar wall thickness $(C)$, or alveolar numeric density $(D)$.

(Fig. 4). Compared with controls, IL-1 $\alpha$ increased lung gas volumes at $7 \mathrm{~d}$ but not at $1 \mathrm{~d}$.

\section{DISCUSSION}

Chorioamnionitis, caused by ureaplasmas, Gram-negative or Gram-positive bacteria, is common in cases of premature delivery (25). Analysis of amniotic fluid of women with chorioamnionitis demonstrates increases in multiple cytokines and pro-inflammatory mediators including IL-1 (26). The fetal effects associated with chorioamnionitis include lung injury, lung maturation and brain injury in humans $(27,28)$. In this study, we analyzed lung injury and lung maturation responses to direct lung exposure to a single cytokine IL- $1 \alpha$ without the 

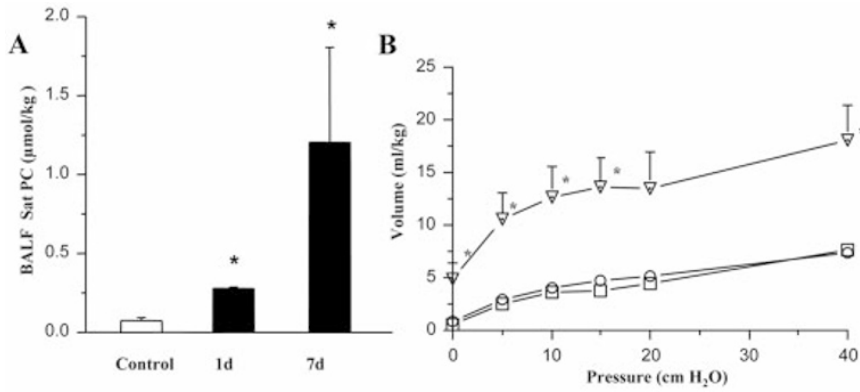

Figure 4. Intratracheal IL-1 induced lung maturation. (A) Amount of saturated phosphatidyl choline (Sat PC) in bronchoalveolar lavage fluid (BALF) was expressed as $\mu \mathrm{mol} / \mathrm{kg}$ body weight for controls $(\square)$ and intratracheal IL- $1 \alpha$ at $1 \mathrm{~d}$ and $7 \mathrm{~d}(\boldsymbol{\square})$. (B) Lung volumes as ( $\mathrm{ml} / \mathrm{kg}$ body weight) versus pressure in $\mathrm{cm}_{2} \mathrm{O}$. Intratracheal IL-1 increased BAL Sat PC and lung volumes at $7 \mathrm{~d}(\nabla)$ relative to controls $(\mathrm{O})$ or a $1 \mathrm{~d}$ intratracheal IL-1 $\alpha$ exposure ( $\square$ ). (4-9 animals per group, $* p<0.05$ versus control).

confounding effects of the cascade of inflammatory mediators resulting from chorioamnion inflammation. In fetal sheep, IL-1 $\beta$ mRNA increases soon after intra-amniotic endotoxin or IL- $1 \alpha$ (29). While either IL- $1 \alpha$ or IL- $1 \beta$ when given by intra-amniotic injection can induce lung maturation, IL- $1 \alpha$ is more potent and was chosen as the agonist for these experiments (6).

Intratracheal IL-1 induced acute lung inflammation at 1d (increased cytokines and inflammatory cells) and at 7d monocytes were increased in BALF. This inflammatory response is similar quantitatively and qualitatively to that induced by intratracheal as well as intra-amniotic endotoxin as reported previously by our group $(9,30)$. Interestingly, the fetal lung responds to IL-1 with both inflammation and maturation, but it has no inflammatory or maturational responses to $\mathrm{TNF} \alpha$ (29). While endotoxin inhibited microvascular development and alveolar septation $(12,23)$, the IL-1 induced inflammation did not have much of an effect on markers of microvascular injury and did not interfere with alveolar septation. However, the degree of lung maturation, as indicated by the induction of Sat PC and increases in lung volumes, was similar to intratracheal or intra-amniotic endotoxin-exposed animals (9). However, intratracheal IL- $1 \alpha$ did not induce AOE activity. This lack of response differs from the increase in AOEs in the fetal lung in response to intra-amniotic endotoxin (14). This comparison of the IL-1 and endotoxin responses demonstrates that inflammation can induce lung maturation in the absence of microvascular and septation abnormalities. We speculate that the increased injury and perhaps oxidant stress caused by endotoxin exposure is needed to induce AOE. Antenatal endotoxin exposure results in changes in postnatal inflammatory responses to ventilation (31). There is no information about how antenatal IL-1 might impact postnatal injury responses.

Although endotoxin receptor TLR-4 signaling and IL-1 receptor signaling share common mediators, there are important differences between the signal transduction mechanisms. Activation of TLR-4 recruits myeloid differentiation factor 88 (MyD88) and other adaptor molecules to the receptor complex (32). The IL-1 receptor associated kinases and tumor necrosis factor receptor-associated factor 6 then are activated leading to activation and nuclear translocation of nuclear factor $-\kappa \mathrm{B}$
(NF- $\kappa \mathrm{B})$ resulting in transcription of cytokines and other genes. MyD88 gene knock-out studies in mice demonstrate that IL-1 receptor signaling is completely dependent on MyD88 while LPS signaling can occur by a MyD88independent pathway $(32,33)$. While the TLR-4 signaling via the MyD88-dependent pathway causes an early NF- $\kappa \mathrm{B}$ activation, TLR-4 signaling via the MyD88-independent pathway leads to delayed NF- $\kappa \mathrm{B}$ activation and transcription of interferon and interferon responsive genes. The signal transduction pathways initiated by TLR-4 or IL-1 receptor activation have not been studied in fetal tissues.

Previous studies from our laboratory demonstrate that responses of the fetal lung to IL-1 and endotoxin differ in a number of ways. The recruitment of inflammatory cells to the fetal lung is CD-18 ( $\beta 2$ integrin) dependent for endotoxin, but not for IL-1 (11). Intra-amniotic endotoxin induces the interferon-responsive genes IP-10 and MIG in the fetal lung, while intra-amniotic IL-1 does not (34). We also previously reported that intra-amniotic endotoxin strikingly induces the AOEs (14) and the results from this study show that intratracheal endotoxin causes modest increases in CAT and GP. In contrast, intratracheal IL- $1 \alpha$ had no effect on AOE. Other signaling pathways also can induce both inflammation and lung maturation. For example, live ureaplasmas, which presumably signal via TLR2 and TLR6 receptors, and endotoxin from periodontal organisms also can induce lung maturation in the fetal sheep $(35,36)$. These results demonstrate that inflammatory responses, downstream injury, and maturational responses in the fetal lung can differ with different proinflammatory agents. Further, these new results demonstrate that lung maturation can result from the direct signaling of the fetal lung by a single cytokine and the antecedent inflammatory cascade from chorioamnionitis is not required.

In most experimental models, an increase in AOEs was linked to other lung maturational responses (2). Maternal or fetal exposures to corticosteroids induce the AOEs in sheep and all other species evaluated to date (37). We report that AOEs are induced by intra-amniotic and intratracheal endotoxin, but not intratracheal IL-1. Of note, the induction of AOE by intratracheal endotoxin was less striking than the response to intra-amniotic endotoxin (14). The inflammatory response as assessed by inflammatory cells in BALF did not differ much for intratracheal and intra-amniotic endotoxin compared with intratracheal or intra-amniotic IL-1 (9). A difference in the characteristics of the inflammatory responses or in oxidant products of those responses may explain why intratracheal IL-1 did not induce the AOE. The important point is that AOEs may not increase despite lung inflammation and lung maturation. The clinical corollary is that inflammation induced lung maturation may not protect the infant from oxygen mediated injury. Fetal lung AOEs increase in late gestation in parallel with increases in plasma cortisol and surfactant lipids (2). In contrast to corticosteroids, thyroid hormones induce the surfactant system but suppress the simultaneous increases in lung AOEs $(38,39)$. Thus, maturational agents need not induce parallel increases in surfactant and AOE. 


\section{REFERENCES}

1. Burri PH 1997 Structural aspects of prenatal and postnatal development and growth of the lung. In: McDonald JA (ed) Lung Growth and Development. Marcel Dekker, Inc., New York, pp 1-35

2. Frank L, Sosenko IR 1987 Prenatal development of lung antioxidant enzymes in four species. J Pediatr 110:106-110

3. Crowley P 2005 Prophylactic corticosteroids for preterm birth. Cochrane Database Syst Rev 2000:CD000065

4. Watterberg KL, Demers LM, Scott SM, Murphy S 1996 Chorioamnionitis and early lung inflammation in infants in whom bronchopulmonary dysplasia develops. Pediatrics 97:210-215

5. Jobe AH, Newnham JP, Willet KE, Moss TJ, Gore Ervin M, Padbury JF, Sly P, Ikegami M 2000 Endotoxin induced lung maturation in preterm lambs is not mediated by cortisol. Am J Respir Crit Care Med 162:1656-1661

6. Willet K, Kramer BW, Kallapur SG, Ikegami M, Newnham J, Moss T, Sly P, Jobe A 2002 Intra-amniotic injection of IL-1 induces inflammation and maturation in fetal sheep lung. Am J Physiol Lung Cell Mol Physiol 282:L411-L420

7. Kallapur SG, Willet KE, Jobe AH, Ikegami M, Bachurski C 2001 Intra-amniotic endotoxin: Chorioamnionitis precedes lung maturation in preterm lambs. Am J Physiol Lung Cell Mol Physiol 280:L527-L536

8. Newnham JP, Kallapur SG, Kramer BW, Moss TJ, Nitsos I, Ikegami M, Jobe AH 2003 Betamethasone effects on chorioamnionitis induced by intra-amniotic endotoxin in sheep. Am J Obstet Gynecol 189:1458-1466

9. Moss TJ, Nitsos I, Kramer BW, Ikegami M, Newnham J, Jobe A 2002 Intra-amniotic endotoxin induces lung maturation by direct effects on the developing respiratory tract in preterm sheep. Am J Obstet Gynecol 187:1059-1065

10. Kawai T, Akira S 2005 Toll-like receptor downstream signaling. Arthritis Res Ther 7:12-19

11. Kallapur SG, Moss JT, Newnham JP, Ikegami M, Jobe AH 2005 Recruited inflammatory cells mediate endotoxin-induced lung maturation in preterm fetal lambs. Am J Respir Crit Care Med 172:1315-1321

12. Kallapur SG, Bachurski CJ, Le Cras TD, Joshi SN, Ikegami M, Jobe AH 2004 Vascular changes following intra-amniotic endotoxin in preterm lamb lungs. Am J Physiol Lung Cell Mol Physiol 287:L1178-L1185

13. Kramer BW, Ikegami M, Moss TJ, Nitsos I, Newnham JP, Jobe AH 2005 Endotoxininduced chorioamnionitis modulates innate immunity of monocytes in preterm sheep. Am J Respir Crit Care Med 171:73-77

14. Sosenko IR, Jobe AH 2003 Intra-amniotic endotoxin increases lung antioxidant enzyme activity in preterm lambs. Pediatr Res 53:679-683

15. Kallapur SG, Nitsos I, Moss TJ, Kramer BW, Newnham J, Ikegami M, Jobe AH 2005 Chronic endotoxin exposure does not cause sustained structural abnormalities in the fetal sheep lungs. Am J Physiol Lung Cell Mol Physiol 288:L966-L974

16. Mason RJ, Nellenbogen J, Clements JA 1976 Isolation of disaturated phosphatidylcholine with osmium tetroxide. J Lipid Res 17:281-284

17. Bartlett GR 1959 Phosphorus assay in column chromatography. J Biol Chem 234:466-468

18. McCord JM, Fridovich I 1969 Superoxide dismutase. An enzymic function for erythrocuprein (hemocuprein). J Biol Chem 244:6049-6055

19. Holmes RS, Masters CJ 1970 Epigenetic interconversions of the multiple forms of mouse liver catalase. FEBS Lett 11:45-48
20. Paglia DE, Valentine WN 1967 Studies on the quantitative and qualitative characterization of erythrocyte glutathione peroxidase. J Lab Clin Med 70:158-169

21. Richards GM 1974 Modifications of the diphenylamine reaction giving increased sensitivity and simplicity in the estimation of DNA. Anal Biochem 57:369-376

22. Scherle WF 1970 A simple method of volumetry of organs in quantitative stereology. Mikroskopie 26:57-60

23. Willet KE, Jobe AH, Ikegami M, Brennan S, Newnham J, Sly PD 2000 Antenatal endotoxin and glucocorticoid effects on lung morphometry in preterm lambs. Pediatr Res 48:782-788

24. Halliday HL 1999 Clinical trials of postnatal corticosteroids: inhaled and systemic Biol Neonate 76:29-40

25. Goldenberg RL, Hauth JC, Andrews WW 2000 Intrauterine infection and preterm delivery. N Engl J Med 342:1500-1507

26. Yoon BH, Romero R, Jun JK, Park KH, Park JD, Ghezzi F, Kim BI 1997 Amniotic fluid cytokines (interleukin-6, tumor necrosis factor-alpha, interleukin-1 beta, and interleukin-8) and the risk for the development of bronchopulmonary dysplasia. Am J Obstet Gynecol 177:825-830

27. Dammann O, Leviton A 2000 Brain damage in preterm newborns: biological response modification as a strategy to reduce disabilities. J Pediatr 136:433-438

28. Van Marter LJ, Dammann O, Allred EN, Leviton A, Pagano M, Moore M, Martin C Developmental Epidemiology Investigators 2002 Chorioamnionitis, mechanical ventilation, and postnatal sepsis as modulators of chronic lung disease in preterm infants. J Pediatr 140:171-176

29. Ikegami M, Moss TJ, Kallapur SG, Mulrooney N, Kramer BW, Nitsos I, Bachurski C, Newnham JP, Jobe AH 2003 Minimal lung and systemic responses to TNFa in preterm sheep. Am J Physiol Lung Cell Mol Physiol 285:L121-L129

30. Kramer BW, Moss TJ, Willet K, Newnham J, Sly P, Kallapur SG, Ikegami M, Jobe A 2001 Dose and time response after intra-amniotic endotoxin in preterm lambs. Am J Respir Crit Care Med 164:982-988

31. Ikegami M, Jobe A 2002 Postnatal lung inflammation increased by ventilation of preterm lambs exposed antenatally to E.coli endotoxin. Pediatr Res 52:356-362

32. Palsson-McDermott EM, O'Neill LA 2004 Signal transduction by the lipopolysaccharide receptor, Toll-like receptor-4. Immunology 113:153-162

33. Adachi O, Kawai T, Takeda K, Matsumoto M, Tsutsui H, Sakagami M, Nakanishi K, Akira S 1998 Targeted disruption of the MyD88 gene results in loss of IL-1- and IL-18-mediated function. Immunity 9:143-150

34. Kallapur SG, Jobe AH, Ikegami M, Bachurski CJ 2003 Increased IP-10 and MIG expression after intra-amniotic endotoxin in preterm lamb lung. Am J Respir Crit Care Med 167:779-786

35. Newnham JP, Shub A, Jobe AH, Bird PS, Ikegami M, Nitsos I, Moss TJ 2005 The effects of intra-amniotic injection of periodontopathic lipopolysaccharides in sheep. Am J Obstet Gynecol 193:313-321

36. Moss TJ, Nitsos I, Ikegami M, Jobe AH, Newnham JP 2005 Experimental intrauterine Ureaplasma infection in sheep. Am J Obstet Gynecol 192:1179-1186

37. Walther FJ, Jobe AH, Ikegami M 1998 Repetitive prenatal glucocorticoid therapy reduces oxidative stress in the lungs of preterm lambs. J Appl Physiol 85:273-278

38. Sosenko IR, Lewis PL, Frank L 1986 Metyrapone delays surfactant and antioxidant enzyme maturation in developing rat lung. Pediatr Res 20:672-675

39. Sosenko IR, Frank L 1987 Thyroid hormone depresses antioxidant enzyme maturation in fetal rat lung. Am J Physiol 253:R592-R598 